\title{
FILOLOGÍA VERDE Y POÉTICA DE LA RESPIRACIÓN PARA UN MUNDO CONTAMINADO
}

\section{GREEN PHILOLOGY AND POETICS OF BREATHING IN A POLLUTED WORLD}

\author{
José Manuel Marrero Henríquez \\ Universidad de Las Palmas de Gran Canaria
}

\section{ABSTRACT}

The ecological crisis of the Anthropocene gives philology an excellent opportunity to rise from its ashes and become green and strong before the cultural studies that have dethroned it from its venerable position. Grounded upon the speculative development of a poetics of breathing, a general theory of literature of ecological roots, green philology turns its attention towards new fields of critical search and academic interest, and, by doing so, it contributes to enrich its own area of knowledge, which has been reluctant to environmental scientific research.

Keywords: Green Philology, Poetics of Breathing, Ecocriticism, Cervantes, Dialogue of the Dogs 


\section{RESUMEN}

La plena conciencia de realizarse en las circunstancias ecológicamente críticas de un siglo XXI plenamente antropocénico ofrece a la filología una excelente oportunidad para renacer de sus cenizas y hacerse tan figuradamente verde como fuerte frente a los estudios culturales que la han ido apeando de su venerable trono. Asentada en el desarrollo especulativo de una poética de la respiración, una teoría general de la literatura de inspiración ecológica, la filología verde se orienta hacia objetivos de interés crítico y áreas de atención académica nuevos y, al hacerlo, contribuye al enriquecimiento de una disciplina que se ha mostrado reticente a la exploración de territorios literarios de indagación científica de inspiración medioambientalista.

Palabras clave: Filología verde, poética de la respiración, ecocrítica, Cervantes, Diálogo de los perros

Fecha de recepción: 10 de noviembre de 2021.

Fecha de aceptación: 15 de diciembre de 2021.

Cómo citar: Marrero Henríquez, José Manuel (2021): «Filología verde y poética de la respiración para un mundo contaminado», en Actio Nova: Revista de Teoría de la Literatura y Literatura Comparada, 5: 417-435.

DOI: https://doi.org/10.15366/actionova2021.5.017 


\section{INTRODUCCIÓN}

El pensamiento ecologista ofrece una oportunidad para la renovación «ambiental» de las Humanidades que la filología no debe desaprovechar. Entendida tanto en la primera como en la segunda acepción con que el DRAE la define, en tanto «ciencia que estudia las culturas tal y como se manifiestan en su lengua y en su literatura, principalmente a través de los textos escritos» y en cuanto «técnica que se aplica a los textos para reconstruirlos, fijarlos e interpretarlos», la filología, inspirada por la ecología, tiene el camino desbrozado para hacerse verde y dar pasos decididos hacia la provechosa actualización de sus cometidos tradicionales. Con plena conciencia de realizarse en las circunstancias antropocénicas del siglo XXI, la filología, al tornarse figuradamente verde y ecológicamente sensible, tiene una excelente oportunidad para renacer de sus cenizas y hacerse fuerte frente a los estudios culturales que la han ido apeando de su venerable trono.

No se trata de ocupar el lugar de los estudios culturales ni de emular sus estrategias, tampoco se trata de modificar los cometidos filológicos con el objetivo de adaptarlos de manera frívola a los usos y costumbres de lo bío, eco, verde, sostenible y circular. Nada sería más pernicioso para la filología que caer en modas que más pronto que tarde habrán de mostrar que lo que parecía sólido cimiento no era más que decorado de cartón piedra. Porque hay que admitir que lo verde, lo ecológico, lo sostenible, aunque sin duda responden con seriedad académica y científica a los retos medioambientales del siglo XXI, pueden también funcionar como atractivas etiquetas al exclusivo servicio de intereses de mercado.

La filología verde se afirma como filología y se reafirma como verde con honestidad. No es una filología oportunista. Su objetivo declarado es el estudio de la cultura y de sus manifestaciones literarias a partir de una conciencia medioambiental que responde ética y estéticamente a las circunstancias ecológicamente críticas del momento. Y no por ello renuncia a mirar al pasado para encontrar raíces en una tradición postergada. El horizonte de expectativas de esta filología parte del presente y expande su perspectiva hacia el ayer para descubrir afinidades estéticas e ideológicas para las que la cultura ha reservado un lugar subsidiario y para rastrear huellas conducentes hacia visiones de vida alternativas que han quedado desdibujadas y críticamente desatendidas, si no borradas, por la idea hegemónica de que el mundo está al servicio del ser humano y de que el progreso está directamente vinculado al crecimiento constante de la producción y el consumo. 


\section{HORIZONTE DE EXPECTATIVAS VERDE}

La filología verde es a la preocupación ecológica del siglo XXI lo que la novela experimental fue al positivismo del siglo XIX, una consecuencia del contexto en que se produce y que viene determinado por una serie de advertencias científicas que se suceden desde 1972 hasta la actualidad, bien entrado ya el siglo XXI, y que anuncian el colapso del sistema de producción y consumo del capitalismo globalizado. Tales advertencias calan en la sociedad y en la política contemporáneas porque los avanzados sistemas de prospectiva y la tecnología de observación y computarizada han dibujado un escenario de precariedad y dificultades de supervivencia para la humanidad del que los medios informativos y la industria audiovisual se han venido haciendo eco con frecuencia creciente. Es simbólico de esta conciencia global el hecho de que en 1969 alguien puso el pie sobre la luna y desde allí pudo observar por primera vez el planeta Tierra como un solo sistema de relaciones. Es por ello la filología verde un vástago más de una crisis ecológica que ha supuesto, tal y como afirma Rolf Peter Sieferle, un desafío para las ciencias y las humanidades:

En primer lugar, se [...] planteó la cuestión [de la crisis ecológica] a las ciencias naturales, que debían responder a cuestiones urgentes sobre los valores límite o las relaciones causales. Los economistas habían de enfrentarse al conflicto tantas veces evocado entre «economía y ecología»; por su parte, los juristas debieron desarrollar un nuevo derecho ambiental, la ciencia política debía clarificar las condiciones institucionales para la protección del medio ambiente y a los filósofos y teólogos se les exigió la formulación de una ética ecológica. (2001: 35)

El horizonte de expectativas verde — Jauss dixit— de esta filología se expande más allá de los tres hitos recientes señalados, la visión global que en 1969 se tiene de la Tierra desde la luna, la publicación en 1972 de Los límites al crecimiento, y el refrendo que las advertencias de ese estudio ha encontrado en estudios posteriores, como, por ejemplo, los informes que el IPCC (Panel Intergubernamental del Cambio Climático, sus siglas en inglés) viene ofreciendo periódicamente desde su fundación en 1988 hasta hoy, bien entrada la centuria XXI. En el ámbito de la economía el horizonte alcanza el siglo XVIII, cuando tras la confianza en el crecimiento sin límites preconizado con optimismo por Adam Smith en $A n$ Inquiry into the Nature and Causes of the Wealth of Nations (1759) mediante el desarrollo de la división del trabajo y de la maquinización, surgen las tesis de Malthus y Ricardo, «concretamente [el problema planteado por] la relación recursos/población, de Malthus, y la 
ley de los rendimientos decrecientes, de Ricardo» (Tamames, 1974: 24), que son las tesis que posibilitarán que, setenta años después, en 1848, en el capítulo IV de Principles of Political Economy, John Stuart Mill pueda referirse con toda claridad al «estado estacionario» y declare que espera, «para bien de la prosperidad, que los partidarios del estado progresivo se conformarán con ser estacionarios mucho antes de que la necesidad les obligue a ello» (Tamames, 1974: 24) ${ }^{1}$.

«¿A qué punto último tiende la sociedad con su progreso industrial? ¿Cuando el progreso cese, en qué condiciones podemos esperar que dejará a la humanidad?» (Tamames, 1974: 22). Stuart Mill entiende que es deseable llegar a un estado estacionario, que al final del estado progresivo habrá de llegarse a una estabilidad, y se manifiesta como un precedente tanto del concepto de homeostasis de los ecosistemas, la tendencia de los ecosistemas a resistir las transformaciones y a mantenerse en un estado de equilibrio, que Frederic Edward Clements expone en 1905, en la primera obra pedagógica de ecología, Research Methods in Ecology, como de las concepciones de ecosistema de Tansley y de Lindeman que conducirán a dos adelantos importantes, uno proveniente de la física, «la termodinámica del ser vivo, cuyas bases fueron sentadas en 1945 por el físico Schrölinger [...y otro de la informática] la teoría del inventor de la cibernética, Norbert Wiener» (Acot, 1990: 107).

Si, como afirma E. P. Odum, «los organismos vivos, los ecosistemas y la biosfera entera poseen la característica termodinámica esencial de ser capaces de crear y mantener un estado de orden interno o de baja entropía» (Acot, 1990: 115), resulta más que pertinente vincular las reflexiones de política y economía de Stuart Mill sobre el estado estacionario con el informe del MIT para el Club de Roma Los límites al crecimiento de 1972, con las sucesivas prospectivas del IPCC (su sexto ciclo de evaluación se anuncia para septiembre de 2022) y con movimientos contemporáneos contrarios al modelo de desarrollo vinculado al incremento constante de la producción y el consumo como la teoría del decrecimiento del economista francés Serge Latouche y el Slow Food del italiano Carlo Petrini.

\footnotetext{
1 Thomas Robert Malthus en 1798 publicó An Essay on the Principle of Population as It Affects the Future Improvement of Society, with Remarks on the Speculations of Mr. Godwin, $M r$. Condorcet and Other Writers, y en él se refiere a la necesidad de controlar la expansion demográfica para asegurar la futura disponibilidad de alimentos. La tesis que David Ricardo plantea en Principles of Political Economy and Taxation (1817) queda expresada sucintamente en su ley de los rendimientos decrecientes, que afirma que «al aumentar las cantidades de un factor variable (capital o trabajo) aplicadas a una cantidad fija de otro factor (tierra), el incremento en la producción total (cereal) que resulta de cada unidad adicional del factor variable (capital o trabajo) eventualmente irá decreciendo, de modo que con los sucesivos insumos del factor variable (capital o trabajo) se agregarán incrementos decrecientes, cada vez menores, de producto (cereal)» (Tamames, 1974: 16).
} 
Sería una labor enciclopédica de gran interés localizar todas las fuentes de la visión ecosistémica contemporánea en que la filología verde podría inspirarse ${ }^{2}$. En cualquier caso, y antes de acometer esa ingente tarea, es posible concluir, tal y como señala E. P. Odum en fecha tan temprana como 1953, en Fundamentals of Ecology, y en palabras de Pascal Acot, que de manera definitiva tales fuentes conducen a que

la teoría de los ecosistemas sustituy[a] un espacio ecológico dividido por un espacio ecológico reunificado, en el cual los factores abióticos y bióticos del medio ya no representan más que dos aspectos de una misma realidad. Y como todo cambio importante en el orden científico va acompañado de una modificación de nuestra forma de ver el mundo, [...] el desarrollo y las aplicaciones de la teoría de los ecosistemas provocarán la aparición de una idea ecologista sistémica que transformará las representaciones sociales de las relaciones naturaleza-sociedad en las sociedades industrializadas. (1990: 109)

Todos los caminos conducen a la nueva Roma de la conciencia ecosistémica que se extiende a escala global, conciencia que está en el horizonte de la filología verde y que George Sessions califica de «ecocéntrica» en la introducción del imprescindible volumen que edita en 1995, Deep Ecology for the 21st Century, y en la que enmarca el citado texto de Stuart Mill. Sessions considera que ha habido tres grandes oportunidades históricas que Occidente no ha sabido aprovechar para abandonar el camino de la «desviación antropocéntrica» y volver al «ecocentrismo presocrático»: en el Medioevo, el pensamiento del filósofo judío Maimónedes y el de San Francisco de Asís; en el siglo XVII, la metafísica panteísta de Spinoza y, en el siglo XIX, el pensamiento de Parson Thomas Malthus, John Stuart Mill y, junto a ellos, Henry David Thoureau, George Perkins Marsh, John Muir y George Santayana, y una serie de autores que se adentran en el siglo XX, Betrand Russel, Aldous Huxley y Arne Naess, entre otros. Según Sessions, el fracaso de San Francisco permitió que

\footnotetext{
${ }^{2}$ No obstante, tal pesquisa supera con creces el objetivo de estas páginas pues esas fuentes son inagotables, vienen de lejos y provienen de ámbitos diversos, desde la economía, la política, la física y la cibernética a la botánica, la geografía y la geología. De manera sucinta cabría señalar que a inicios del siglo xIX Humboldt añade a la catalogación de plantas el interés por el clima como la causa que explica la distribución geográfica de los vegetales, que Alphonse de Candolle, en su Geografia de 1855, se interesa por las vegetaciones previas y el papel de las rocas subyacentes y de los suelos para el estudio de la distribución vegetal, que la idea de evolución en el ámbito de la geología que Charles Lyell postula en 1832 en Principles of Geology abre paso al evolucionismo de Darwin y posteriormente al de Haeckel, el creador del término «ecología», que, como afirma Pascal Acot, es quien utiliza el término «por primera vez en una nota a pie de página de la obra Generelle Morphologie der Organismen» (1990: 36) y que en su segundo volumen «da la definición más célebre de ecología: [...] la totalidad de la ciencia de las relaciones del organismo con el medio, que comprende en sentido amplio, todas las ‘condiciones de existencia» (Acot, 1990: 37). En el camino a la visión ecosistémica juegan también un papel de relevancia el término «biocenosis» con que Möbius en 1877 «designa una comunidad de seres vivos», pues es el concepto científico que, en palabras de Pascal Acot, por primera vez permite pensar en «una entidad biológica integrada por elementos que pertenecen a dos Reinos diferentes», el vegetal y el animal (1990: 94).
} 
el antropocentrismo judeocristiano se perpetuara en los sistemas filosóficos de Bacon, Descartes y Leibniz y se combinara y reforzara con el humanismo antropocéntrico del Renacimiento [...y que el] humanismo renacentista [...] continuara con los filósofos de la Ilustración y en el siglo Xx con Karl Marx, John Dewey y el existencialismo humanista de Jean-Paul Sartre ${ }^{3}$. (1995: 160-161)

Y la ciencia moderna, que pudo rescatar la cosmología no antropocéntrica presocrática, primero en la astronomía, con el heliocentrismo, la infinidad del universo y la evolución cósmica, y luego en la biología, con la evolución darwinista, no logró erradicar la matriz antropocéntrica del cristianismo y del humanismo que inspiran su propósito de dominar y conquistar la Naturaleza (Sessions, 1995: 162).

A la visión de Sessions, tan certera como poco alentadora, convendrá añadir que existen resquicios para la ilusión y por los que se cuelan iniciativas de las artes y las ciencias sinceramente verdes, sinceramente sostenibles, sinceramente pensadas en favor de la homeostasis del ecosistema planetario y de una cultura que la salvaguarde. Las emergentes Humanidades Ambientales son un signo de esperanza y, en su marco, también la filología verde que estas páginas postulan y proponen practicar.

\section{FiLOLOGÍA VERDE}

La filología verde responde a las circunstancias medioambientales del momento insertándose en esa tradición que Sessions considera postergada y que ahora, en plena era del antropoceno, adquiere relieve. Y lo hace de una manera que bien puede calificarse de «ecológicamente cervantina» precisamente porque se sitúa en el presente y en él justifica su razón de ser de la misma manera que Don Quijote reafirma el valor de su carácter caballeresco en su propia modernidad.

Recuérdese que cuando don Quijote se ve enjaulado, sucio y maloliente, de vuelta a su casa, considera que su voluntad no puede haber sido doblegada por el engaño de sus vecinos, el cura y el barbero, tal y como Sancho le advierte, sino por un encantamiento, pues su sometimiento y su dudosa condición higiénica, aunque no acordes con las tradiciones de la caballería andante, podrían deberse a que «con el tiempo [los encantamentos] se hubiesen mudado de unos en otros, y que agora se use que los encantados hagan todo lo que yo hago,

3 Todas las traducciones son mías. 
aunque antes no lo hacían. De manera que contra el uso de los tiempos no hay que argüir ni de qué hacer consecuencias».

La filología verde se mira en el espejo de ese don Quijote que, sucio y maloliente, se presenta renovado y acorde a los tiempos que corren en contraste con las viejas expectativas de la tradición caballeresca. No en vano es en sus circunstancias poco higiénicas en las que Don Quijote se reconoce como ejemplo para caballeros por venir pues entiende que las inmundicias que decoran sus peripecias indican que esas peripecias superan a las hasta entonces realizadas por otros caballeros de manera tal que lo hacen merecer un lugar en la historia de la literatura como un clásico de las lenguas modernas. En una reflexión de lúcida reivindicación don Quijote pregunta a Sancho: «¿qué quieres que diga o piense sino que la manera de mi encantamento excede a cuantas yo he leído en todas las historias que tratan de caballeros andantes que han sido encantados?».

El adjetivo «verde» no sólo hace hincapié en el rasgo cervantino de la actividad filológica que se realiza con conciencia del presente, en plena crisis ecológica, en un planeta tan contaminado como la fétida jaula de Don Quijote; también implica una valoración vehemente y positiva de las potencialidades científicas de la filología que califica, pues los trabajos filológicos realizados bajo la perspectiva verde pueden, como don Quijote frente a la tradición caballeresca, «exceder a cuant $[\mathrm{o}] \mathrm{s}$ yo he leído en tod[o]s» los trabajos filológicos precedentes. Sin perder su identidad, al reverdecer, la filología ha de encontrar, como Don Quijote en su jaula, un lugar fértil en el que renovar su labor centenaria, desarrollar con nuevos objetivos sus cometidos tradicionales e inscribirse con pleno derecho en el marco de las emergentes Humanidades Ambientales ${ }^{4}$.

La filología verde no se muerde la lengua, sino que expone con tanto atrevimiento como coherencia académica y científica sus logros. Desoye la nueva censura en que se ha constituido, tal y como considera Darío Villanueva en Morderse la lengua, el pensamiento

\footnotetext{
${ }^{4}$ La filología verde no pretende ser provocativa y moderna por el mero hecho de serlo, no quiere convertirse en un espectáculo, no desea adoptar gestos superficiales de ruptura ni acomodarse de manera frívola y advenediza a la mercadotecnia de la cultura académica (Lakoff y Johnson). La filología verde quiere introducir el factor ecología dentro de los intereses académicos propios de su disciplina. ¿Acaso no fueron las tentaciones de considerar de manera rígida el canon y el desprecio de intereses académicos alternativos los que apearon a la filología del lugar privilegiado que tuvo en los planes de estudio de un pasado reciente? Y no sólo en los campus universitarios de los Estados Unidos, tal y como Harold Bloom manifestó al criticar con resentimiento los estudios culturales en su férrea defensa del canon literario occidental contra el feminismo y contra los emergentes estudios raciales y postcoloniales. También en los planes de estudio y en los nombres nuevos adoptados por los grados que han derivado de las antiguas licenciaturas de las universidades españolas los grados «filológicos» se han pronunciado con boca chica y se han transformado en titulaciones en lenguas y literaturas.
} 
políticamente correcto, provenga éste de actitudes inmovilistas o provenga de llamadas a la radicalidad más extrema. Y lo hace sobre los tres pilares de la teoría, la crítica y la historia de la literatura, todos permeados por las preocupaciones medioambientales del momento.

La filología verde presta su atención a la poética de la que emanan los textos del pasado y también escoge la eco-poética que permite reinterpretarlos en el presente y hacerlos útiles al futuro, no sólo analiza la retórica empleada para persuadir a los lectores de ayer sino también las inexploradas posibilidades de seducción para los lectores de mañana. Y para sustentar esas actividades críticas e historiográficas que le son propias, la filología verde adopta una teoría que enlaza las formas literarias con las ideologías a ellas adheridas, una teoría que es global y ecuménica, que considera que los textos literarios forman parte del ecosistema planetario y que en tal ecosistema respiran. La literatura no es en esta teoría sino un resultado sofisticado de la evolución natural, una expresión cultural de la belleza y del ritmo y de la armonía que albergan en la Naturaleza y que son su razón de ser. Esa teoría de la literatura, que he denominado poética de la respiración, entiende que la dicotomía cultura/naturaleza no es tal sino un continuo animado por la respiración, una respiración que es compartida, real y figurada a un tiempo, y de cuyo compás y cadencia depende la salud de la cultura y de la vida.

\section{POÉTICA DE LA RESPIRACIÓN}

La poética de la respiración afirma que hay una relación íntima entre el ritmo y armonía que se dan en la naturaleza y el ritmo y la armonía que se dan en la poesía en particular y en la literatura y las artes en general. Ritmo y armonía no sólo son cualidades formales que dan cadencia al poema y estructura a la novela, son también cualidades propias de la vida del planeta Tierra. Es la poética de la respiración no sólo una poética, esto es, una disciplina que se ocupa de la naturaleza, principios y finalidad de la poesía y la literatura, sino también una eco-poética, pues la manera en que la poética de la respiración entiende los principios y finalidades de la literatura está influida por la conciencia de la crisis ecológica planetaria que afecta a los tiempos que corren y por el temor al colapso sistémico a que conduce la manera imperante de entender el bien y el progreso.

La poética de la respiración es una eco-poética exigente, que responsabiliza a las formas literarias de que sus logros estéticos y las propuestas ideológicas, morales y éticas que 
entrañan casen con las necesidades de equidad y justicia de una sociedad que se proyecta hacia el futuro de manera des-carbonizada. De ahí la caracterización de poética de la respiración, pues la respiración pone en relación la escritura literaria y la actividad crítico-literaria con el ritmo vital del planeta Tierra. No en vano, ritmo y armonía son, de manera sustancial y evidente en la poesía, y también en la literatura en general, dos características fundamentales que poesía y literatura comparten con el ritmo y la armonía que se sustancian en la Naturaleza: las mareas, las estaciones, el dibujo que las olas dejan en la arena, los estratos que se revelan en el corte de un acantilado, el ciclo menstrual, el pálpito del corazón, el día y la noche, las estaciones, el año, las formas pétreas de la lava solidificada, la cadencia de la inhalación y la exhalación del aire que es el respirar.

Literatura y poesía, en la era del antropoceno, tienen la responsabilidad de dar a los lectores la posibilidad de hacerlos respirar junto con el planeta Tierra y de favorecer el ritmo acompasado de ambos. Y la poética de la respiración se compromete a alentar esa vinculación largamente debida, pues es una eco-poética que entraña una manera de entender la literatura y la poesía que conduce a poner en la crítica literaria una lente que le permita descubrir, por presencia u omisión, el pálpito deseable que un texto debe contener en las tapas del libro para contribuir al bien común que ha de ir de la mano de la salud ecológica planetaria. Incluso cuando un libro se resiste a ello, incluso si su militancia es hostil, violenta y contaminante, la lente de la poética de la respiración tenderá a reciclarlo y transformarlo en una manifestación cultural ecológicamente aprovechable. A tal acción invita Jonathan Bate cuando se pregunta «qué ocurre si miramos los poemas como si fuesen parques imaginarios en los que podemos respirar un aire que no es tóxico y en los que nos acomodamos a un modo de habitar no alienado» $(64)^{5}$.

\footnotetext{
${ }^{5}$ A diferencia de la poética de la respiración, que es una teoría de la literatura que se expone como tal, la mayoría de las manifestaciones de eco-poética se encuentra dispersa e implícita en aquellos trabajos de crítica e historia crítica de las literaturas hispánicas y en estudios culturales ibéricos que están relacionados con asuntos medioambientales que han captado el interés de determinadas manifestaciones artísticas. La eco-poética se encuentra implícita en trabajos sobre la relevancia de las voces de la Tierra en algunos poetas españoles contemporáneos (Galas, 2020), sobre las narrativas acerca de enclaves rurales abandonados y de las migraciones campo-ciudad (Álvarez Méndez, 2019) y sobre un amplio abanico de acercamientos a la presencia de los animales en literatura (Carretero-González, 2020; Kerslake, 2016; Lope, 1992; Subercaseaux, 2014; Marrero Henríquez, 2017, 2018, 2020, 2021, 2022; Martin, 2020). La eco-poética puede encontrarse también en la teoría y la práctica de las artes plásticas con preocupaciones medioambientales (Albelda et al., 2018). En sentido amplio, la ecopoética afecta a los estudios culturales que analizan los escenarios imaginarios del post-desarrollo para poner en cuestión el capitalismo y la destrucción metabólica de la diversidad cultural y biológica (Prádanos, 2019), la devastación de los paisajes bajo el efecto de la industria turística (Santa Ana), la regulación nacional de asuntos de índole biopolítica, como las corridas de toros (Beilin, 2015), y la comprensión cultural de la naturaleza y los textos legales sobre el paisaje y la caza (Ares-López, 2019). En un sentido mucho más amplio, la ecopoética tiene una presencia relevante en las investigaciones que estudian los problemas del «desarrollo»
} 
Inspirada por las especulaciones de Jorge Wagensberg sobre las regularidades rítmicas y armónicas que naturaleza y arte comparten, la poética de la respiración, de manera explícita, considera que las obras literarias pertenecen al sistema homestático de la cultura, tanto si provienen del ámbito español, hispánico, latinoamericano u occidental, como si están vinculadas a cosmogonías indígenas, de filiación cristiana o atea, o si provienen de raíces orales, letradas o virtualmente digitales.

En una poética de la respiración la literatura es el resultado sofisticado del instinto de la vida o, en otras palabras, de la búsqueda de la belleza entendida en tanto herramienta fundamental para la supervivencia. Porque las recurrencias de la belleza no sólo son estéticamente relevantes, también son una propiedad de la naturaleza que se pone de manifiesto en las formas biológicas caracterizadas por patrones de orden en el tiempo y en el espacio. La belleza de la estructura fractal de las plantas y el sistema vascular de los animales está omnipresente en la biología de la vida, porque la biología necesita de regularidades para tener éxito en el sostenimiento de la vida. El encuentro eco-crítico de estas regularidades, a veces difíciles de aprehender, depende de las aptitudes estéticas que son la esencia de un placer mental que cuando lee busca y exhibe la misma cantidad de ritmo y armonía que la naturaleza tiene.

Con el advenimiento de la cultura letrada, incluso con el advenimiento del alfabetismo multimedia y digital del que se nutre la ciberpoesía, la poética de la respiración considera que la crítica no debe olvidar el itinerario que va de la oralidad a la escritura, al menos si la crítica quiere ser ecológicamente relevante. Todas las literaturas, sea la latinoamericana que se nutre de las tradiciones de los pueblos originarios de América y de sus ideologías y cosmovisiones, sean la española, la europea y la latinoamericana enraizadas en la cultura occidental, respiran. Las palabras respiran, y la ecocrítica tiene el deber de buscar, analizar e interpretar los procedimientos mediante los cuales los textos respiran o, con otras palabras, mediante los cuales están vinculados a los patrones rítmicos de la naturaleza, sea cual fuere la tradición a la que pertenezcan (Skowronski, 2015).

económico, ética animal, la industria alimentaria, el género y los valores, las sociedades post-carbono, y temas relacionados, desde que éstos son todos asuntos culturales de gran relevancia para las narrativas y poesías ecológicamente comprometidas. 
Un eJemplo y tres alternativas: Cervantes animalista, Cervantes Vegano, Cervantes postcolonial

La poética de la respiración invita a poner en juego una manera de leer Coloquio de los perros que hace de la situación de crisis ecológica contemporánea el fundamento de una investigación filológica que es necesariamente crítica y necesariamente histórica. Histórica porque la investigación escudriña en la posibilidad de encontrar vestigios de la sensibilidad medioambiental del presente no sólo en el texto cervantino sino también en precedentes que lo pudieran haber influido y en sucesores que lo pudieran haber emulado. Crítica porque la investigación escudriña en los aspectos específicos que hacen del Coloquio una obra de gran interés literario y gran valor eco-pedagógico, dulce y útil a un tiempo, una obra que respira al unísono con la naturaleza y pone sobre la palestra los males sociales derivados de la arrogante idea de la excepcionalidad humana que afectan a la sociedad de su época y que perviven en el presente.

El meollo de la cuestión «verde» sobre la que Cervantes polemiza en Coloquio de los perros es la idea de que el ser humano es el ser privilegiado de la Creación por poseer habla y razón. De hecho, los perros, al comienzo del Coloquio, cuando aún no han salido de su asombro por poder hablar, corroboran esa excepcionalidad al comentar que «no solamente hablamos, sino [...] que hablamos con discurso, como si fuéramos capaces de razón, estando tan sin ella que la diferencia que hay del animal bruto al hombre es ser el hombre animal racional, y el bruto, irracional».

No obstante, pasadas unas páginas y sucedidos algunos episodios, las cosas comienzan a verse de una manera muy diferente. El ser humano no parece ser tan superior, no suele ser fiable ni tampoco socialmente beneficioso, al contrario, es moralmente débil y fácilmente corruptible, y ni siquiera por disponer de habla ha de ser inteligente y racional. Cuando los perros conversan sobre el uso de latines innecesarios, Cipión afirma «que hay algunos que no les escusa el ser latinos de ser asnos», y Berganza asiente: «¿Quién lo duda? La razón está clara, pues cuando en tiempo de los romanos hablaban todos latín, como lengua materna suya, algún majadero habría entre ellos, a quien no escusaría el hablar latín dejar de ser necio».

Cervantes cuestiona la excepcionalidad de ese ser humano que se considera la cúspide del universo que Dios puso a su disposición en el Génesis bíblico y también cuestiona la idea de que tal excepcionalidad radica en que lenguaje y razón van juntos y que 
tanto Pico della Mirandola en su Discurso sobre la dignidad bumana (1486) como Descartes en su Discurso del método (1637) defendieron antes y después de la publicación del Coloquio (1613). La duda cervantina es de especial pertinencia a la hora de vincular el Coloquio con la ética animalista contemporánea y de releerlo a la luz de los debates sobre la racionalidad de los animales considerados no objetos sino seres sintientes, debates que han conducido en las últimas décadas a modificar la entidad de los animales en las leyes, a salvaguardar sus derechos y a protegerlos frente al maltrato.

¿Es Cervantes un animalista a la actual usanza? Evidentemente no puede serlo. No obstante, la consideración de Berganza, un animal de mayor valor social e inteligencia más viva que la de muchos de los personajes humanos que pueblan el Coloquio, lo emparenta con la ética animal contemporánea. ¿Es Cervantes vegano? Evidentemente no puede serlo, no obstante, la industria cárnica y el consumo de carne es el origen de todos los males en el Coloquio. Los jiferos son gente capaz de asesinar sin pensárselo dos veces, tan acostumbrados están a la sangre en los mataderos, los alguaciles y los jueces, soportes fundamentales del orden social, son fácilmente sobornados con piezas de carne; los pastores matan al ganado haciendo ver que es el lobo para robar la carne, la carne es el objeto codiciado ante el cual cualquier atisbo de moralidad se desvanece. ¿Es Cervantes postcolonial? Evidentemente no. No obstante, la alta consideración que el Coloquio muestra por los perros Cipión y Berganza permite afirmar sin temor a error que Cervantes está del lado del oprimido, del lado de quien, carente de habla, posee inteligencia y sentimientos o, en otros términos, del indígena que es considerado un animal sin alma porque, como el Calibán de La tempestad, carece del conocimiento del habla del conquistador.

\section{CONCLUSIONES}

La que he llamado filología verde responde a la definición de filología del DRAE, «ciencia que estudia las culturas tal y como se manifiestan en su lengua y en su literatura, principalmente a través de los textos escritos», pero en tanto verde orienta su espacio de investigación hacia aquellos lugares en los que los textos literarios pueden ser de especial interés desde una perspectiva medioambiental. En el caso de Cervantes, ha llamado poderosamente la atención el radical cuestionamiento que se da en Coloquio de los perros de la excepcionalidad del ser humano fundamentada en la razón y en el habla, entre otros motivos 
porque actualiza la poética horaciana y la mantiene dulce y útil en los tiempos antropocénicos que corren.

Y la actualiza y la mantiene dulce y útil porque el Coloquio tiene potencialidades significativas para situaciones imprevistas. Del cuestionamiento de la excepcionalidad humana a emparentar el texto cervantino, en primer lugar, con la ética animal contemporánea, en segundo lugar, con actitudes veganas que pueden entenderse como un compromiso extremo con esa ética y, en tercer lugar, con la posibilidad de hacer una lectura postcolonial del Coloquio, van unos trechos fácilmente salvables. Ahí está la poética de la respiración para ayudar a ese tránsito, a la vez crítico e historiográfico, ahí están los cínicos, y Plutarco, a quien Cervantes leyó y que en el siglo I en sus Moralia se admiraba de la inteligencia de los animales y advertía de lo nefasto del consumo de carne, y Montaigne que desde su siglo «cervantino» y en la Apología de Raimundo Sabunde se pregunta si no será su gata la que juega con él y si no será ella la que se interrogue por la inteligencia del ser humano, y también desde su siglo «cervantino» Shakespeare, que en La tempestad presenta a Calibán, el otro sometido por no hablar la lengua del amo, y entrado ya el siglo XVIII, Feijoo, que se sorprende de la inteligencia de los brutos e identifica los cálculos de una gata para alcanzar el jamón que cuelga en lo alto con los que un hombre en esas circunstancias haría, y ahí está el gran desconocido Francisco González Díaz, que a caballo de los siglos XIX y XX fue llamado «apóstol del arbolado» y un acérrimo defensor de los animales, y Miguel Delibes, que en 1975, en su discurso de ingreso en la RAE, dio sentido a toda su obra en virtud de una consideración de progreso contraria al incremento constante de la producción y el consumo. Y ahí están Thoureau, y London, y Coetzee con Las vidas de los animales y tantos y tantos otros.

La filología reverdecida observa con admiración al lúcido Cervantes en el papel de animal sin habla, amarrado como un perro maltratado o como un indígena sin alma en su encierro de Argel. Y lo rescata de esa prisión para hacer de su obra un lugar en el que los lectores respiren al unísono con la naturaleza, un lugar en el que líneas de pensamiento de ayer y por venir se encuentren para contribuir al conocimiento de una cultura a través de sus textos y al bien común. 


\section{BIBLIOGRAFÍA}

Acot, Pascal (1990): Historia de la ecología, Madrid, Taurus.

Albelda, José, José M ${ }^{a}$ Parreño y José Manuel Marrero Henríquez (eds.) (2018): Humanidades ambientales. Pensamiento, arte y relatos para el Siglo de la Gran Prueba, Madrid, Catarata.

Ares-López, Daniel (2019): «Culturas de la naturaleza y naturalezas-culturas: hacia una redefinición de los estudios culturales desde el antropoceno», en Arizona Journal of Hispanic Cultural Studies, 23: 215-234.

Bate, Jonathan (2000): The Song of the Earth, Cambridge, Harvard University Press.

Beilin, Katarzyna (2015): In Search of an Alternative Biopolitics: Anti-Bullfighting, Animality, and the Environment In Contemporary Spain, Athens, Ohio University Press.

Bloom, Halrold (2006): El canon occidental, Barcelona, Anagrama.

Boletin Oficial del Estado (16 de diciembre de 2021). https://www.boe.es/boe/dias/2021/12/16/pdfs/BOE-A-2021-20727.pdf (último acceso 02/10/2021).

Carretero-González, Margarita (ed.) (2020): Spanish Thinking about Animals, East Lansing, Michigan State University Press.

Cervantes, Miguel de (1613): Coloquio de los perros: http://www.cervantesvirtual.com/obravisor/el-coloquio-de-los-perros--0/html/ff31b1bc-82b1-11df-acc7002185ce6064_32.html (último acceso 02/10/2021).

Cervantes, Miguel de (1605, 1615): El ingenioso bidalgo Don Quijote de la Mancha: https://cvc.cervantes.es/literatura/clasicos/quijote/edicion/parte1/cap49/defaul t.htm (último acceso 02/10/2021).

Cervantes, Miguel de (2019): Información de Argel, edición de Adrián J. Sáez, Madrid, Cátedra. Coetzee, J. M. The Lives of Animals. New Jersey: Princeton University Press, 2017.

Delibes, Miguel (1988): El mundo en la agonía, Barcelona, Círculo de Lectores.

Descartes, René (2011): Discurso del método, Madrid, Alianza.

Feijoo, Benito Gerónimo (1845): Teatro crítico universal, Tomo III, Madrid, Imprenta de Ayguals de Izco Hermanos.

Gala, Candelas (2020): Ecopoéticas. Voces de la tierra en ocho poetas de la España actual, Salamanca, Ediciones de la Universidad. 
González Díaz, Francisco (2005): Árboles. Una campaña periodística, edición de José Manuel Marrero Henríquez, Las Palmas de Gran Canaria, Ediciones del Cabildo.

González Díaz, Francisco (2007): Cultura y turismo, edición de José Manuel Marrero Henríquez, Las Palmas de Gran Canaria, Ediciones del Cabildo.

IPCC: https://www.ipcc.ch (último acceso: 02/10/2021).

Jauss, Hans Robert (1982): Toward and Aesthetic of Reception, Minneapolis, University of Minnesota Press.

Kerslake Young, Lorraine (2016): «From Aesop to Arcadia: Raising Ecocritical Awareness through Talking Animals in Children's Literature», en Marrero Henríquez, José Manuel (ed.) (2015): Transatlantic Landscapes. Environmental Awareness, Literature and the Arts, Alcalá, UAH-Franklin Institute: 209-222.

Lakoff, George y Mark Johnson (2017): Metáforas de la vida cotidiana, Madrid, Cátedra.

Lope, Hans-Joachin (1992). «La racionalidad de los brutos. El Padre Feijoo ante el problema de la vivisección», en Antonio Vilanova (coord.), Actas del X Congreso de la Asociación Internacional de Hispanistas, Vol. 2. Barcelona: Promociones y Publicaciones Universitarias, pp. 1185-1192.

Malthus. Thomas Robert (1798): An Essay on the Principle of Population: https://www.gutenberg.org/cache/epub/4239/pg4239-images.html (último acceso: 02/10/2021).

Marrero Henríquez, José Manuel (2022): «Chickens like Celebrities», en Villanueva-Romero, Diana, Lorraine Kerslake et al. (eds.) (2022): Imaginative Ecologies: Inspiring Change through the Humanities, Leiden and Boston, Brill: 217-222.

Marrero Henríquez, José Manuel (2021): «Vegan Cervantes: Meat Consumption and Social Degradation in Dialogue of the Dogs», en Wright, Laura (ed.) (2021): The Routledge Handbook of Vegan Studies, New York, Routledge: 89-100.

Marrero Henríquez, José Manuel (2020): «Affection, Literature, and Animal Ideation». Spanish Thinking about Animals, en Carretero-González, Margarita (ed.) (2020): Spanish Thinking about Animals, East Lansing, Michigan State University Press: 3-19. Marrero Henríquez, José Manuel (2019): «Ecocriticism of the Anthropocene and the Poetics of Breathing», en Marrero Henríquez, José Manuel (ed.) (2019): Hispanic Ecocriticism, Berlin, New York, Peter Lang: 19-48.

Marrero Henríquez, José Manuel (2018): «Ética animal en Coloquio de los perros», en Ocnos, 17.3: 86-94. 
Marrero Henríquez, José Manuel (2017): «Animalismo y ecología: sobre perros parlantes y otras formas literarias de representación animal», en Castilla. Estudios de Literatura, 8: 258-307.

Martin, Adrienne L. (2020): «Animalspeak and the Construction of Character in El coloquio de los perrosi, en Romance Notes 60.3: 479-490.

Mirandolla, Pico della (2006): Sobre la dignidad del hombre, Medellín, Editorialpi.

Montaigne, Michel de (1898): «Apología de Raimundo Sabunde», en Ensayos de Montaigne seguidos de todas sus cartas conocidas hasta el día: http:/ / www.cervantesvirtual.com/obravisor/ensayos-de-montaigne--0/html/fefb17e2-82b1-11df-acc7-

002185ce6064_161.html\#I_85_(último acceso 02/10/2021).

Parreño, José María y José Manuel Marrero Henríquez (2018): «La cultura del antropoceno» en Albelda, Parreño y Marrero Henríquez (eds.) (2018): 7-14.

Pérez Jiménez, Aurelio (1990): «Plutarco y el Humanismo español del Renacimiento», en Pérez Jiménez y Cerro Calderón (eds.) (1990): Estudios sobre Plutarco: obra y tradición. Actas del I Simposio Español sobre Plutarco, Málaga, Universidad: 229-248.

Plutarco (2001): Moralia. Obras morales y de costumbres, edición de Vicente Ramón Palerm y Jorge Bergua Cavero, Madrid, Gredos.

Prádanos, Luis I (2019): «Ecología y estudios culturales ibéricos en el siglo XXI», en Arizona Journal of Hispanic Cultural Studies, 23: 133-144.

Ricardo, David (1817): Principles of Political Economy and Taxation: https://www.gutenberg.org/cache/epub/33310/pg33310-images.html (último acceso: 02/10/2021).

Santa Ana, Mariano de (ed.) (2004): Paisajes del placer, paisajes de la crisis, Taro de Tahíche, Fundación César Manrique.

Sessions, George (ed.) (1995): Deep Ecology for the 21st Century, Boulder, Shambala.

Sieferle, Rolf Peter (2001): «Qué es la historia ecológica», en González de Molina, Manuel y Joan Martínes Alier (eds.) (2001): Naturaleza transformada, Barcelona, Icaria: 31-54.

Skowronski, Ellen (2015): «Words that Breathe. An Interview with José Manuel Marrero Henríquez», en Ecozon@. European Journal of Literature, Culture and Environment, 6.1: 107-117.

Smith, Adam (1759): An Inquiry into the Nature and Causes of the Wealth of Nations: https://www.gutenberg.org/files/3300/3300-h/3300-h.htm (último acceso: 02/10/2021). 
Ue Actio nova: ReVISTA DE TEORÍA DE LA LITERATURA Y LITERATURA COMPARADA, 5: 417-435 DOI: https://doi.org/10.15366/actionova2021.5.017

Stuart Mill, John (1885): Principles of Political Economy: https://www.gutenberg.org/cache/epub/30107/pg30107-images.html (último acceso: 02/10/2021).

Subercaseaux, Bernardo (2014): «Perros y literatura: condición humana y condición animal», en Atenea 509: 33-62.

Tamames, Ramón (1974): La polémica sobre los límites al crecimiento, Madrid, Alianza.

Villanueva, Darío (2021): Morderse la lengua Corrección política y posverdad, Madrid, Espasa.

Wagensberg, Jorge (2004): «Beauty and Intelligibility», en Marx, Mina y Manuel Sevilla (eds.) (2004): Fernando Casás. Arqueología del no-lugar, Madrid, Círculo de Bellas Artes: 187194.

Zola, Emile (2002): El Naturalismo, edición de Jaume Fuster, Barcelona, Península. 
SOBRE EL AUTOR

\section{José Manuel Marrero Henríquez}

Escritor, poeta y ensayista, José Manuel Marrero Henríquez es una figura reconocida de la ecocrítica hispánica y europea. Profesor de Teoría de la Literatura y Literatura Comparada de la Universidad de Las Palmas de Gran Canaria, ha publicado numerosos trabajos sobre la representación paisajística y animal en la literatura y sobre diversos tópicos y autores de las tradiciones literarias de España y Latinoamérica.

Contact information: jose.marrero@ulpgc.es 